\title{
Butyrylcholinesterase as Biomarker of Occupational Exposure Among Female Cotton Workers
}

\author{
Aima Iram Batool ${ }^{1 *}$, Syeda Humaira Jabeen ${ }^{1}$, Naima Huma Naveed ${ }^{2}$, Fayyaz Ur Rehman ${ }^{3}$, Iram Inayat ${ }^{1}$, \\ Fareeha Idrees $^{1}$, Asma Noreen ${ }^{1}$, Hakim Bibi ${ }^{1}$
}

\begin{abstract}
Objectives: Lack of safety measures and unawareness about the harmful effects associated with pesticide exposure among cotton picking females contribute to poor health quality in this group of workers. The activity of butyrylcholinesterase (BChE) acts as potential biomarker of pesticide exposure among these females. Our study aimed to determine the relationship between decreasing activity of BChE level in serum with pesticide exposure in female cotton pickers that can lead towards health impairments. Materials and Methods: The BChE level in serum samples of 50 female cotton pickers were compared to that of 50 controls using the $t$ test. A questionnaire was prepared and asked from each female worker which was related to precautionary measures, work history and personal information.

Results: Serum BChE activity in exposed females was (6194.80 U/L) as compared to non-exposed females (7209.77 U/L). Our studies confirm and extend the association between educed BChE activity and pesticide exposure. BChE activity could be used as an assessment tool for pesticide poisoning among exposed workers. In regard to precautionary measures none of the females used gloves or eye glasses. Face mask was used by only $10 \%$ of the females for protection. $30 \%$ of the females did not take bath or wash their hands and face after picking, and almost all females were found to eat and drink during picking.

Conclusion: Pesticide exposure along with no safety measures decreased the BChE activity among exposed female workers that could be responsible for deranging the physiological responses of their body.

Keywords: Acetylcholinesterase, Butyrylcholinesterase, Female, Pesticides
\end{abstract}

\section{Introduction}

Millions of tons of cotton are hand-picked by women and girls every year in cotton growing belts of Pakistan particularly starting in October and extending to the end of January. Female labors of all age groups are engaged in cotton picking with the youngest being 6-8 years old. An elated percentage of cotton pickers belong to countrified areas, generally the poorer strata of population with an average of 8 hours working and $50-100 \mathrm{~kg}$ of cotton picked per day.

In addition to low payoff, longer employed hours and steely job, these females are also exposed to pesticides sprayed heavily on cotton crop (1). Fear of pests such as whitefly and American bollworm, prompt farmers to use pesticides even during the cotton picking period. Relating to health risks, out of 2.6 million working females (cotton pickers), annually 2.2 million females get sick due to exposure to pesticides used on cotton fields. In Pakistan female cotton pickers are more prone to pesticides exposure because $95 \%$ do not have/use any of the precautionary measures (2). Furthermore cuts and skin rashes during work make those females more susceptible to pesticides hazards by absorption via dermal route.

Picking cotton is common during pregnancy and breast feeding which poses additional risk to the health of the women and their children (3). The most common health problems which majority of the female cotton pickers suffer include headache $(80 \%)$, tingling in body parts $(66.70 \%)$, sweating $(63.30 \%)$, muscular weakness (73.30\%) and skin allergies (53.30\%).

Observing butyrylcholinesterase (BChE) and hematologic parameters of an agriculture worker can be an effective indicator for checking health hazards associated with pesticides exposure (4). BChE inhibition was proved as a good bio-indicator to determine pesticide poisoning by the World Health Organization (WHO). With its protective role against pesticides, $\mathrm{BChE}$ hydrolyzed the active ingredient of these agents making them unable to inhibit acetylcholinesterase (AChE) (5). Several studies have verified the correlation between pesticide exposure and $\mathrm{BChE}$ inhibition (6-9). Serum BChE is a sensitive enzyme for measuring pesticides poisoning, shows various level of inhibition, $20-50 \%, 80-90 \%$ and over $90 \%$ relatives to mild, moderate and sever poisoning respectively.

Hemoglobin $(\mathrm{Hb})$ level of a pesticide exposed person decreases sufficiently (10). Concentration of blood hemoglobin reduces in females due to pesticide exposure (11). The low level of $\mathrm{Hb}$ may be due to binding of organophosphorus pesticides with iron followed by a lack of incorporation of iron in hemoglobin (12). 
This study aimed to determine the level of BChE in serum of female cotton pickers and establishing a correlation between serum BChE and pesticide exposure as they vary inversely with each other.

\section{Materials and Methods}

Two stations namely Multan, and Mianwali were selected for this study. Samples were collected randomly from Khaniwal (Multan) and Dohaba (Mianwali) which have long history of cotton production and identified as extensive cotton growing areas of Pakistan.

\section{Study Design and Target Population}

A total of 100 females were recruited for study after getting written consent from them. All the females had similar socio-economical status and there was no major difference in their diet and living conditions. These females were categorized into exposed and non-exposed groups. Each category was composed of 50 individuals. The non-exposed group consisted of those females which never indulged in agricultural work or were never directly exposed to pesticides. They were only involved in household chores. The exposed group was also composed of 50 females from Multan and Mianwali areas, 25 females from each. These females were involved in cotton picking for more than 2 years and spend 8 hours in the fields, daily. The study was carried out from December to mid of January.

\section{Blood Sampling}

Blood samples were collected from each subject under study. Eight milliliters blood sample was collected by using sterilized disposable syringes from sub-clavian vein of all volunteers. Serum was separated within an one hour of sample collection; each centrifuge tube had

$5 \mathrm{ml}$ of clotted blood which was placed in centrifuge machine and centrifuged at $10000 \mathrm{rpm}$ for separation of serum. Serum samples were stored at $-20^{\circ} \mathrm{C}$. Serum samples were analyzed for BChE enzyme activity for exposed and non-exposed population.

\section{Principle}

Cholinesterase hydrolyses butyrylthiocholine into thiocholine and butyric acid. Thiocholine further reduces yellow potassium hexacyanoferrate (III) to colorless potassium hexacyanoferrate. The decrease of absorbance is measured at $405 \mathrm{~nm}$. This test was performed on Merck micro lab 200.

\section{Material}

Regents (component and concentration):

R1: pyrophosphate $\mathrm{pH}$ 7.6, $95 \mathrm{mmol} / \mathrm{L}$

Potassium hexacyanoferrate (III), $2.5 \mathrm{mmol} / \mathrm{L}$

R2: butyrylthiocholine, $75 \mathrm{mmol}$.

Assay Procedure

Measured quantity of $5 \mathrm{~mL}$ of $\mathrm{R} 1$ and $20 \mathrm{~mL}$ of R2 were mixed together to prepare the working reagent. Out of the working reagent, $1250 \mu \mathrm{L}$ was taken and mixed with $20 \mu \mathrm{L}$ of each sample. Without any delay this prepared sample was ingested in Merck micro lab 200 and after 5 minutes reading was recorded.

Statistical analysis

Statistical analysis of data was done by XLSTAT and SPSS. Statistical differences were examined by using analysis of variance (ANOVA) and student $t$ test.

\section{Results}

Table 1 shows the percentage of precautionary measures taken by female cotton pickers during picking. None of the females used gloves or eye glasses during cotton picking. Only $10 \%$ of the females used face mask to protect themselves. Thirty percent of females did not take bath or wash their hands and face after picking. Majority of the female workers ate and drank during picking (100\%).

Regarding the physical status of cotton pickers, $34 \%$ of females were pregnant while $74 \%$ were on practice of feeding babies.

Table 2 shows BChE level which was significantly lower in female cotton pickers as allegorized to females in control group; BChE activity was 6194.80 U/L and 7209.77 U/L, respectively. Highly significant statistical difference in value of $\mathrm{Hb}$ was present between exposed and non-exposed females $(t=5.38, P=0.00)$. Statistically no significant difference was shown in comparison of work duration between cotton-pickers and non-exposed group. Both groups had same work duration with $(P>0.05)$. Number of abortions was greater in cotton pickers than non-exposed females, but statistically no significant difference was seen according to numbers of abortions. In cotton picker average weight was $44.10 \mathrm{~kg}$ which was much higher in non-exposed group $(51.93 \mathrm{~kg})$.

Table 2 shows $(P<0.05)$ a significant statistical difference among female cotton pickers and non-exposed groups related to height $(t=2.75, P=0.05)$. Non-significant difference was present between cotton-pickers and non-exposed females according to number of children and abortion.

\section{Discussion}

Pakistan is an agriculture based country but due to lack of knowledge, careless attitude, and rough practice in han-

Table 1. Precautionary Measure Taken by Cotton Pickers Females During Picking and Their Physical Status

\begin{tabular}{lcc}
\hline Precautions & Number & Percent \\
\hline Use gloves & 0 & 0 \\
Use mask & 5 & 10 \\
Use eye glasses & 0 & 0 \\
Cover body & 50 & 100 \\
Wear shoes & 15 & 34 \\
Eat and drink & 50 & 100 \\
Wash hands and face after picking & 35 & 70 \\
Pregnanant & 15 & 34 \\
Breast feeding & 37 & 74 \\
\hline
\end{tabular}


Table 2. Comparative Analysis Between Cotton Picker and Non-exposed Females

\begin{tabular}{|c|c|c|c|c|c|c|}
\hline & Group & Mean & SD & SE & $t$ & $P$ \\
\hline \multirow{2}{*}{ Age } & Cotton picker & 35.80 & 14.27 & 2.61 & \multirow{2}{*}{$4.28^{* *}$} & \multirow{2}{*}{0.00} \\
\hline & Non-exposed & 23.57 & 6.41 & 1.17 & & \\
\hline \multirow{2}{*}{ Butyrylcholinesterase } & Cotton picker & 6194.80 & 1422.38 & 259.69 & \multirow{2}{*}{$-2.55^{*}$} & \multirow{2}{*}{0.013} \\
\hline & Non-exposed & 7209.77 & 1649.01 & 301.07 & & \\
\hline \multirow{2}{*}{$\mathrm{Hb}$} & Cotton picker & 10.11 & 1.81 & 0.33 & \multirow{2}{*}{$-5.38 * *$} & \multirow{2}{*}{0.000} \\
\hline & Non-exposed & 12.18 & 1.08 & 0.20 & & \\
\hline \multirow{2}{*}{ Number Of Children } & Cotton picker & 4.19 & 1.89 & 0.41 & \multirow{2}{*}{$2.66^{*}$} & \multirow{2}{*}{0.014} \\
\hline & Non-exposed & 2.00 & 1.26 & 0.52 & & \\
\hline \multirow{2}{*}{ Number Of Abortion } & Cotton picker & 1.90 & 0.88 & 0.28 & \multirow{2}{*}{1.40} & \multirow{2}{*}{0.192} \\
\hline & Non-exposed & 1.00 & 0.00 & 0.00 & & \\
\hline \multirow{2}{*}{ Height } & Cotton picker & 4.99 & 0.19 & 0.04 & \multirow{2}{*}{$-2.75^{* *}$} & \multirow{2}{*}{0.008} \\
\hline & Non-exposed & 5.15 & 0.26 & 0.05 & & \\
\hline \multirow{2}{*}{ Weight } & Cotton picker & 44.10 & 8.89 & 1.62 & \multirow{2}{*}{$-3.688 *$} & \multirow{2}{*}{0.001} \\
\hline & Non-exposed & 51.93 & 7.56 & 1.38 & & \\
\hline
\end{tabular}

** Highly significant; *Significant.

dling of pesticides, farmers face serious health problem to (13). Present investigation was carried out to monitor the health problem among female cotton pickers. Yousaf et al (14) investigated symptoms of pesticide exposure female agriculture workers of Punjab, Pakistan. Data was collected from 50 female cotton pickers by using well-prepared interviewing schedule. Majority of females agreed that they were always facing problems such as stomach disease, breathing problem, diarrhea and swelling of hands and other parts of body during or after picking cotton.

The most economical blood test for checking the hazardous effect of pesticides in agricultural workers exposed to organophosphorus pesticides is serum cholinesterase especially BChE. Its inhibition is taken as a biomarker for exposure. BChE is highly reactive with pesticides; it protects AChE against pesticides. Therefore, serum BChE activity measurement is the most sensitive way to detect pesticide exposure. $\mathrm{BChE}$ is recommended as a biomarker for exposure to organophosphorus pesticides even outside the spraying season (15).

This study showed highly significant decrease in BChE activity in cotton pickers as allegorized to non-exposed group. The observed significant decrease of BChE activity was in accordance with findings of other investigators. Jintana et al (16) suggested that measuring cholinesterase activity could be an admirable biomarker for assessing pesticide exposure and health effect in exposed population. Results of his study showed that there were statistically decrease in BChE activity during high exposure period related to low exposure period. BChE in normal group was higher than in exposed group population. Farahat et al (17) organized the studies to seek out the effect of chlorpyrifos - a widely used organophosphates pesticide - on BChE activity, among agriculture worker. It was established that BChE activity decreased gradually by end of the spraying season. BChE activity remained inhibited even after 8 to 10 days the application of pesticides had ended. The exposure to pesticides was stated as a causative factor for the changes in hemoglobin levels in an earlier study (18). Hb level was also found significantly lower among pesticide exposed females. Among cotton pickers $\mathrm{Hb}$ level was observed as $10.11 \pm 1.81 \mathrm{~g} / \mathrm{dL}$ while the same in non-exposed females was noticed as $12.18 \pm 1.08 \mathrm{~g} / \mathrm{dL}$.

\section{Conclusion}

The our study affirms and extends the connection between reduced $\mathrm{BChE}$ manifestation and pesticides exposure. So, BChE manifestation could be used as a tool for pesticides poisoning among exposed female workers.

\section{Ethical Issues}

The ethical committee of University of Sargodha approved the study.

\section{Conflict of Interests}

The authors declare no conflicts of interests.

\section{Financial Support}

The study was supported by University of Sargodha.

\section{References}

1. Siegmann KA, Shaheen N. Weakest link in the Textile Chain. Pakistani Cotton Pickers' bitter Harvest. The Indian Journal of Labour Economics. 2008;51:619-630.

2. Jabbar A, Mohsin A. Pesticide usage patterns and sideeffects on human health in cotton growing areas of Punjab. 1994.

3. Habib N. Invisible farmers-rural roles in Pakistan The role of women in agriculture leads to direct exposure to pesticides. There is gender bias among policy makers in a society that reinforces the problems. Pesticides News. 1997: 4-5.

4. Iorizzo L, Bianchi A, Gamberini G, et al. Assessment of human exposure to pesticides in greenhouses and effectiveness of personal protective devices. Arh Hig Rada 
Toksikol. 1996;47(1):25-33.

5. Lockridge O, Bartels CF, Vaughan TA, Wong CK, Norton $\mathrm{SE}$, Johnson LL. Complete amino acid sequence of human serum cholinesterase. J Biol Chem. 1987;262: 549-57.

6. Eddleston M, Eyer P, Worek F, Sheriff MR, Buckley NA. Predicting outcome using butyrylcholinesterase activity in organophosphorus pesticide self-poisoning. Qjm. 2008; 101(6):467-474. doi: 10.1093/qjmed/hcn026.

7. Weissmann-Brenner A, Friedman LM, David A, Vidan A, Hourvitz A. Organophosphate poisoning: a multihospital survey. Isr Med Assoc J. 2002;4:573-576.

8. Valle A, O'Connor DT, Taylor P, et al. Butyrylcholinesterase: association with the metabolic syndrome and identification of 2 gene loci affecting activity. Clin Chem. 2006;52:10141020. doi:10.1373/clinchem.2005.065052.

9. Hernández AF, Gómez MA, Pérez V, et al. Influence of exposure to pesticides on serum components and enzyme activities of cytotoxicity among intensive agriculture farmers. Environ Res. 2006;102:70-76.

10. Azmi MA, Naqvi S, Akhtar K, Parveen S, Parveen R, Aslam M. Effect of pesticide residues on health and blood parameters of farm workers from rural Gadap, Karachi, Pakistan. J Environ Biol. 2009;30(5):747-756.

11. Yousef M, El-Demerdash F, Kamel K, Al-Salhen K. Changes in some hematological and biochemical indices of rabbits induced by isoflavones and cypermethrin. Toxicology.
2003;189:223-234.

12. Worthing CR, Hance RJ. The pesticide manual: a world compendium. Farnham, UK: The British Crop Protection Council; 1991.

13. Naqvi S, Jahan M. Pesticide residues in serum and blood samples of the people of Karachi. J Environ Biol. 1999;20:241-244.

14. Yousaf R, Cheema M, Anwar S. Effects of pesticide application on health of rural women involved in cotton picking. Int J Agric Biol. 2004;1:220-221.

15. Khan S, Hemalatha R, Jeyaseelan L, Oommen A, Zachariah A. Neuroparalysis and oxime efficacy in organophosphate poisoning: a study of butyryicholinesterase. Hum Exp Toxicol. 2001;20:169-174.

16. Jintana S, Sming K, Krongtong $\mathrm{Y}$, Thanyachai S. Cholinesterase activity, pesticide exposure and health impact in a population exposed to organophosphates. Int Arch Occup Environ Health. 2009;82:833-842. doi:10.1007/ s00420-009-0422-9.

17. Farahat FM, Ellison CA, Bonner MR, et al. Biomarkers of chlorpyrifos exposure and effect in Egyptian cotton field workers. Environ Health Perspect 2011;119:801.

18. Rugman F, Cosstick R. Aplastic anaemia associated with organochlorine pesticide: case reports and review of evidence. J Clin Pathol. 1990;43:98-101.

Copyright $\odot 2017$ The Author (s); This is an open-access article distributed under the terms of the Creative Commons Attribution License (http://creativecommons.org/licenses/by/4.0), which permits unrestricted use, distribution, and reproduction in any medium, provided the original work is properly cited. 